\title{
Kliniske studier: Får deltakerne god nok skriftlig informasjon?
}

\section{Informasjonsskriv til pasienter som deltar i kliniske} studier kan gjøres lettere å forstå med illustrasjoner, viser en studie ved Oslo universitetssykehus. En tydeligere forside og bedre forklaring av begreper hever også kvaliteten.

Marianne Cecilie Johansen Nævra

Sykepleier og tekniker

Nevrokirurgisk avdeling, Seksjon for klinisk nevrofysiologi, Oslo universitetssykehus

Ketil Berg Olsen

Klinisk nevrofysiolog og overlege

Nevrokirugisk avdeling, Seksjon for klinisk nevrofysiologi, Oslo universitetssykehus

Luis Romundstad

Spesialist i anestesiologi og overlege

Seksjon for anestesiologi, Akuttklinikken, Oslo universitetssykehus

Pål Gunnar Larsson

Klinisk nevrofysiolog og seksjonsleder

Nevrokirurgisk avdeling, Seksjon for klinisk nevrofysiologi, Oslo universitetssykehus

Informasjon Pasient Forskning 
Oslo universitetssykehus inkluderer jevnlig pasienter i forskningsprosjekter, og et stort antall informasjonsskriv blir utlevert til pasientene. I hvilken grad pasientene forstår informasjonen, og mengden og typen informasjon som gis, påvirker deres opplevelse av informasjonsskrivene. Vi ba noen av pasientene om å evaluere informasjonsskrivet de hadde mottatt. De fleste forsto informasjonen i skrivet godt, og de var forn øyd med mengden og typen informasjon. Men illustrasjoner, ytterligere forklaring av begreper og bedre informasjon om det praktiske kan forbedre pasientenes opplevelse av informasjonsskrivet.

I forbindelse med et forskningsprosjekt ved Oslo universitetssykehus (OUS) forespurte vi de samme pasientene som deltok i forskningsprosjektet om å evaluere informasjonsskrivet de hadde mottatt i forbindelse med deltakelsen. Deltakerne i forskningsprosjektet ble da også deltakere i et sideprosjekt som omhandlet evaluering av informasjonsskriv, og som blir beskrevet i denne artikkelen.

\section{Pasientene må få nok informasjon}

Ved OUS er 3000 personer involvert i forskning hvert år, og 2000 artikler blir publisert (1). Pasienter samtykker jevnlig til å delta i forskningsprosjekt, og samtykke- og informasjonsskriv har en sentral rolle ved informasjonsutveksling mellom forskere og pasienter.

Informasjonen til pasienter ved de ulike forskningsprosjektene blir vanligvis gitt både muntlig og skriftlig, for å gi pasienten nok kunnskap til å kunne gi et reelt samtykke $(2,3)$. Hvor mye av den muntlige informasjonen som pasienten oppfatter, er derimot varierende. Vi mener derfor at det er viktig at den skriftlige informasjonen dekker informasjonsbehovet til pasienten.

På generelt grunnlag, med erfaring fra egne forskningsprosjekt og samtaler med pasienter, får vi inntrykk av at enkelte pasienter heller ikke får med seg all informasjonen som står i informasjonsskrivene. Mangel på forståelse av informasjon samt mengde og type informasjon kan være en årsak til suboptimal innsikt (4-8). 


\section{Vi ville kvalitetssikre informasjonsskrivet}

Informasjonsskrivet, der vi spør om pasienten vil delta i vårt forskningsprosjekt, omfatter både informasjon om prosjektet og samtykke ved underskrift.

Bakgrunnen for sideprosjektet var å få bedre kjennskap til pasientenes opplevelse av informasjonen som gis i informasjonsskrivet, og om det er grunnlag for endringer av innholdet for å optimere nytten av informasjonsskrivet. Informasjonsskrivet som ble evaluert, er benyttet ved flere tidligere forskningsprosjekt $(9,10)$ og oppfyller utformingen og informasjonskravene til informasjonsskriv ved OUS (11).

Hensikten med vårt forskningsprosjekt var å kvalitetssikre informasjonsskrivet som vi bruker i egne forskningsprosjekt. Pasientene svarte på et spørreskjema om det aktuelle informasjonsskrivet.

Spørreskjemaet ble utformet av en lege og en sykepleier som var tilknyttet prosjektet, og det ble kvalitetssikret av fem fagpersoner og to pasienter før vi ga det til deltakerne i vårt forskningsprosjekt. Spørsmålene ble utformet for å unders $\varnothing$ ke hvordan pasientene opplever informasjonsskrivet i forhold til forståelse, mengde og type informasjon og deltakelse.

\section{Helsepersonell har et informasjonsansvar}

Pasienter har rett til informasjon $(5,12)$, og helsepersonell har ansvar for at pasientene har forstått innholdet og betydningen av informasjonen i de ulike informasjonsskrivene $(13,14)$.

Krav til utforming av informasjonsskriv (11) og pasientenes behov for informasjon er viktige elementer som forskeren må ta hensyn til i et forskningsprosjekt. Men det oppleves vanskelig, kanskje umulig for forskere, å utforme et informasjonsskriv som tilfredsstiller både retningslinjer for utforming og innhold, samt dekker de ulike pasientene sine informasjonsbehov (3).

\section{Språket er vanskelig å forstå}

Pasienter uttrykker at helseinformasjon er vanskelig å forstå $(4,7,15,16)$. Dette bekreftes av pasienter som har henvendt seg til Norsk pasientforening (5), som uttrykker at språket er vanskelig og informasjonsmengden er for stor. På den andre siden nevnes det at det kan være informasjon de savner. 
En studie (6) viser til at informasjonsskriv kan være for omfattende og ikke tilpasset pasienter. Berger påpeker i sin doktorgrad (8) at lengden på informasjonsskrivene har $\varnothing \mathrm{kt}$, med flere ord og formaliteter. Pasienter oppga i den sammenheng at de ikke kjente til betydningen av alle fagtermene.

Informasjon må individualiseres (17), og et aktuelt spørsmål er hvorvidt det er mulig å utforme et informasjonsskriv som kan passe alle. Det oppfordres til kontinuerlig arbeid (18) samt at pasienter inkluderes i utvikling av informasjonsskriv $(5,16,19-22)$.

\section{Pasientene ble spurt om å delta}

Forskningsprosjektet ved OUS hadde oppstart i februar 2019 og pågikk til juni 2019. I samme periode forespurte vi de samme pasientene som deltok i forskningsprosjektet, om å delta i sideprosjektet med å evaluere informasjonsskrivet de hadde mottatt i forbindelse med deltakelsen.

Inklusjon av pasienter til det aktuelle forskningsprosjektet foregikk samme dag som operasjonen, og informasjonsskrivet ble utlevert og innhentet av anestesilegen ved deltakelsen i prosjektet.

Sykepleierne spurte pasientene om de ville delta i en evaluering av informasjonsskrivet de hadde fătt, dagen etter at pasienten hadde blitt operert. Sykepleierne leverte spørreskjemaet til pasienten og samlet det inn samme dag.

\section{三 «Både anestesilege og sykepleiere var tilknyttet forskningsprosjektet.»}

Både anestesilegen og sykepleierne var tilknyttet forskningsprosjektet. Pasientene fikk muntlig informasjon om forskningsprosjektet når de ble spurt om de ville delta, og alle pasientene leste gjennom informasjonsskrivet. Begge prosjekter foregikk parallelt og inkluderte 20 pasienter.

Det ble gjennomført en kvantitativ observasjonell prospektiv studie, der målet var å forespørre alle pasientene som deltok i forskningsprosjektet, om å delta i sideprosjektet med å evaluere informasjonsskrivet de hadde fått før operasjonen. Svarene fra spørreskjemaet ble innsamlet, registrert og systematisert etter forståelse, informasjon og deltakelse. Data er analysert med deskriptive frekvensanalyser. 


\section{De fleste forsto informasjonen i skrivet}

De fleste (95 prosent) av deltakerne svarte at de forsto informasjonen i informasjonsskrivet. Dette samsvarer ikke med andre studier og tilbakemeldinger fra pasienter $(4,5,7$, $15,16)$ som viser til at helseinformasjonen er vanskelig å forstå og at språket er vanskelig.

Til tross for resultatene fra vår undersøkelse og på bakgrunn av hva andre studier viser til, reflekterte vi rundt hvorvidt man kan forvente, og med sikkerhet vite at pasienter forstår informasjonen i en situasjon hvor det mest sannsynlig er både smerter og engstelse til stede.

\section{$\equiv$ ¿Samtykkekompetanse kan falle helt eller delvis bort dersom pasienten ikke er i stand til å forstå innholdet i informasjonsskriv.»}

Pasient- og brukerrettighetsloven (13) og helseforskningsloven (23) viser til at samtykkekompetanse kan falle helt eller delvis bort dersom pasienten ikke er i stand til å forstå innholdet i informasjonsskriv som blir gitt.

Det henvises til fysiske eller psykiske forstyrrelser, som kan være tilfelle for mange pasienter som skal til en operasjon. Det er ikke uvanlig at pasientene føler smerte, er engstelige og er påvirket av beroligende og/eller smertestillende medisiner. Pasientenes helsetilstand $b \varnothing r$ derfor vurderes før de blir spurt om å delta i et forskningsprosjekt.

\section{Noen savnet informasjon om prosjektet}

Resultatene fra vår unders $\varnothing$ kelse viser at de fleste pasientene var fornøyd med mengde og type informasjon i informasjonsskrivet. Pasientene savnet noe informasjon, og funnet samsvarer med det pasienter har gitt tilbakemeldinger på til Norsk pasientforening (5). Ved vårt prosjekt savnet enkelte pasienter informasjon rundt det praktiske ved gjennomføring av forskningsprosjektet.

I skrivet som pasientene mottok var det praktiske ved gjennomføringen av prosjektet beskrevet under avsnittene: «Hva innebærer studien», «Mulige fordeler og ulemper» og «Kap A», som er et ekstra kapittel på slutten av skrivet, med utfyllende informasjon. Tilbakemeldinger fra pasientene viser at informasjon om det praktiske ikke kom godt nok frem. 


\section{Hva kan vi gjøre bedre?}

I spørreskjemaet fikk pasientene mulighet til å komme med forbedringsforslag til fremtidig utforming av informasjonsskrivet, både ved fritekst og i en avkrysningstabell. Tilbakemeldingene handlet om at forskerne burde benytte illustrasjoner, og at forskerne burde informere mer rundt det praktiske ved prosjektgjennomføringen.

\section{«15 prosent av pasientene ønsket kortere tekst.»}

I en avkrysningstabell med seks alternativer, kommer det frem at 15 prosent av pasientene ønsket kortere tekst, 30 prosent $\varnothing$ nsket bilde/illustrasjon i teksten, 10 prosent $\varnothing$ nsket forklaring av begreper og 5 prosent $\varnothing$ nsket utfyllende overskrifter.

Det ble også utformet tre ulike typer informasjonsskriv A, B og C, som ble vist til pasientene etter at de hadde besvart spørreskjemaet, slik at de kunne gi tilbakemelding på hvilket skriv de foretrakk (tabell 1).

Tabell 1. Informasjonsskriv

\begin{tabular}{|c|c|c|}
\hline Forside type $\mathrm{A}$ & Forside type B & Forside type $C$ \\
\hline Bakgrunn og hensikt & $\begin{array}{l}\text { Vi ønsker å finne ut hva som skjer i } \\
\text { hjernen under anestesi. }\end{array}$ & $\begin{array}{l}\text { Vi ønsker å finne ut hva som skjer i } \\
\text { hjernen under anestesi. }\end{array}$ \\
\hline Hva innebærer studien & $\begin{array}{l}\text { Vi ønsker å registrere hjernens aktivitet } \\
\text { fra hodebunnen under anestesi. }\end{array}$ & $\begin{array}{l}\text { Vi } \varnothing \text { nsker å registrere hjernens aktivitet } \\
\text { fra hodebunnen under anestesi. }\end{array}$ \\
\hline Mulige fordeler og ulemper & $\begin{array}{l}\text { Vi vil før operasjon klistre fast } \\
\text { elektroder i hodebunnen. }\end{array}$ & $\begin{array}{l}\text { Vi vil før operasjon klistre fast } \\
\text { elektroder i hodebunnen. }\end{array}$ \\
\hline $\begin{array}{l}\text { Hva skjer med prøvene og } \\
\text { informasjonen om deg? }\end{array}$ & $\begin{array}{l}\text { Vi vil etter operasjonen analysere } \\
\text { endringer i hjernens nettverk. }\end{array}$ & $\begin{array}{l}\text { Vi vil etter operasjonen. analysere } \\
\text { endringer i hjernens nettverk. }\end{array}$ \\
\hline \multirow[t]{2}{*}{ Frivillig deltakelse } & $\begin{array}{l}\text { Det er frivillig deltakelse og du kan } \\
\text { trekke deg når som helst. }\end{array}$ & $\begin{array}{l}\text { Det er frivillig deltakelse og du kan } \\
\text { trekke deg når som helst. }\end{array}$ \\
\hline & & $\begin{array}{l}\text { Det vil ikke være mulig å identifisere } \\
\text { deg i resultatene av studien når disse } \\
\text { publiseres. }\end{array}$ \\
\hline $\begin{array}{l}\text { Tre ulike informasjonsskriv } \mathrm{me} \\
\text { hvor pasientene skulle velge } \mathrm{c}\end{array}$ & $\begin{array}{l}\text { de som ble vist for pasientene, } \\
\text { e foretrakk. Pasientene foretrakk type C. }\end{array}$ & \\
\hline
\end{tabular}

De ulike informasjonsskrivene ble utformet med ulik mengde tekst og/eller mer utfyllende og forklarende overskrifter på forsiden, men med ellers få forskjeller. Hensikten var å unders $\varnothing$ ke om mengden og typen tekst på forsiden var avgjørende for hva pasientene mente om informasjonsskrivet. Pasientene syntes ikke det var så stor forskjell på informasjonsskrivene, men informasjonsskriv $\mathrm{C}$ ble foretrukket av flest pasienter. 
Informasjonsskrivet (type C) hadde kun enkelte beskrivende setninger om prosjektets temaer på forsiden. Pasientene kunne lese utdypende informasjon om prosjektet på de neste sidene, hvis de ønsket det. Når sykepleierne snakket med pasientene, sa pasientene at dette skrivet var enkelt å forholde seg til, og at de fikk nok informasjon med kun beskrivende setninger på forsiden.

\section{Vi har fått ny innsikt}

Styrken ved sideprosjekt er at vi har fått innsikt i hvordan pasienter opplevde informasjonsskrivet vi benyttet $i$ vårt forskningsprosjekt når det gjelder forståelse, mengde og type informasjon. Vi involverte pasienter i prosessen med å evaluere informasjonsskrivet og svarene vil påvirke utformingen av fremtidige informasjonsskriv.

\section{三 «Svarene vil påvirke utformingen av fremtidige informasjonsskriv.»}

Sideprosjektet ble gjennomført parallelt med et forskningsprosjekt ved OUS der det skulle inkluderes 20 pasienter. Utvalget til vårt prosjekt besto også av 20 pasienter, og det lave antallet svekker generaliserbarheten. I studien innhentet vi opplysninger kun fra en avdeling ved OUS, og vi evaluerte bare en type informasjonsskriv. Dette svekker muligheten til å generalisere funnene.

Det vil alltid være en usikkerhet i forhold til på hvilket grunnlag pasientene svarte på spørreskjemaet, om de svarte basert på skriftlig og/ eller muntlig informasjon, når informasjonsflyten mellom pasient, lege og sykepleier som regel består av både muntlig og skriftlig informasjon. Vi anser likevel at hensikten med prosjektet er oppnådd, da de to prosjektene ble gjennomført på lik måte, i samme tidsrom og at de samme personene var involvert i begge prosjekter.

\section{Konklusjon}

Prosjektet har bidratt til å gi bedre innsikt i hvordan pasienter opplever informasjonsskrivet til det aktuelle forskningsprosjektet og viser at pasientene får god, nok og forståelig informasjon.

Vi har registrert tilbakemeldinger fra pasienter relatert til forbedring av informasjonsskrivet, som indikerer at pasientene foretrekker informasjonsskriv med en tydeligere forside, bruk av illustrasjoner, bedre forklaring av begreper og bedre informasjon om praktisk gjennomføring. 


\section{Referanser}

1. Bakke P. Norges største aktør innen medisinsk og helsefaglig forskning. Oslo: OUS; 2019. Tilgjengelig fra: https://ekspertsykehusetblog.wordpress.com/https://eksperts ykehusetblog.wordpress.com/2019/08/o9/norges-storsteaktor-innen-medisinsk-og-helsefaglig-forskning/ (nedlastet 25.02.2020).

2. Johnson A, Sandford J, Tyndall J. Written and verbal information versus verbal information only for patients being discharged from acute hospital settings to home. Cochrane Database Syst Rev. 2003;(4):CDoo3716.

3. Ferguson PR. Information giving in clinical trials: the views of medical researchers. Wiley Online Library.

2003;17(1):101-11.

4. Edwards M, Hill S, Edwards A. Health literacy-achieving consumer 'empowerment' in health care decisions. Oxford: Oxford University Press; 2009 s. 101-7.

5. Norsk pasientforening. Jeg trenger informasjon. Oslo: Norsk pasientforening; 2019. Tilgjengelig fra: https://www.pasient.no/pasienters-problemer/jeg-trengerinformasjon/ (nedlastet 25.02.2020).

\section{Rokstad IS. Relevant informasjon til} forskningsdeltakere. Tidsskr Nor Legeforen. 2013;4(133):392.

7. $\quad$ Svorkdal MBH. Ordbruken er såpass komplisert at jeg sliter med å forstå hva det betyr. Opdalingen. 16.12.2017. Tilgjengelig fra:

https://www.opdalingen.no/meninger/2017/12/16/Ordbrukener-s\%C3\%A5pass-komplisert-at-jeg-sliter-med-\%C3\%A5forst\%C3\%A5-hva-det-betyr-15764831.ece (nedlastet 25.02.2020).

8. Berger O. Informing cancer patients. (Doktoravhandling). Trondheim: Fakultet for medisin og helsevitenskap, NTNU; 2017.

9. Juel BE. Electrophysiological markers of consciousness: measures of connectivity, complexity, and signal diversity in EEG for distinguishing between conscious and unconscious brain states. (Doktoravhandling). Oslo: Oslo universitet; 2019. 
10. Juel BE, Romundstad L, Kolstad F, Storm JF, Larsson

PG. Distinguishing anesthetized from awake state in patients: A new approach using one second segments of raw EEG.

Front Hum Neurosci. 2018;12:40.

11. Oslo universitetssykehus. Samtykke og forskning. OUS

E-håndbok: OUS nevroklinikken; 2019.

12. Norsk senter for forskningsdata (NSD). Informasjon til utvalget. NSD; 2018 Tilgjengelig fra:

https://nsd.no/personvernombud/hjelp/informasjon_samtykk

e/ (nedlastet 25.02.2020).

13. Lov 2. juli 1999 om rett til medvirkning og informasjon

(pasient- og brukerrettighetsloven). Tilgjengelig fra:

https://lovdata.no/dokument/NL/lov/1999-07-02-

63\#KAPITTEL_3 (nedlastet 25.02.2020).

14. World Medical Association. WMA Declaration of

Helsinki - ethical principles for medical research involving

human subjects. Frankrike: WMA; 2018. Tilgjengelig fra:

https://www.wma.net/policies-post/wma-declaration-of-

helsinki-ethical-principles-for-medical-research-involving-

human-subjects/ (nedlastet 25.02.2020).

15. Flory J, Emanuel E. Interventions to improve research participants' understanding in informed consent for research: a systematic review. JAMA. 2004;292(13):1593-601.

16. Shaw A, Ibrahim S, Reid F, Ussher M, Rowlands G.

Patients' perspectives of the doctor - patient relationship and information giving across a range of literacy levels. Patient Educ Couns. 2009;75(1):114-20.

17. Gulbrandsen P. Informasjon må individualiseres. Tidsskr Nor Legeforen. 2010;130(23):2336.

18. Ruyter KW. Bruk av skjønn for å styrke informasjon og frivillighet. I: Ingjerd I, Fossheim H, red. Etisk skjønn i forskning. Oslo: Universitetsforlaget; 2015. s. 40-9.

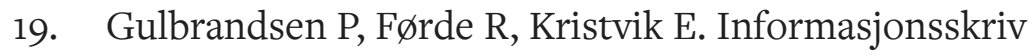
før inngrep. Tidsskr Nor Legeforen. 2010;130(17):1705.

20. Falagas ME, Korbila IP, Giannopoulou KP, Kondilis BK, Peppas G. Informed consent: how much and what do patients understand? Am J Surg. 2009;198(3):420-35. 
21. Sherlock A, Brownie S. Patients' recollection and understanding of informed consent: a literature review. ANZ J Surg. 2014;84(4):207-10.

22. Austvoll-Dahlgren A, Johansen M. Pasienten som medvirker og kunnskapshåndterer. Norsk Epidemiologi. 2013;23(2).

23. Lov 20. juni nr. 44 om medisinsk og helsefaglig forskning (helseforskningsloven). Tilgjengelig fra: https://lovdata.no/dokument/NL/lov/2008-06-20-44 (nedlastet 25.02.2020). 